\title{
Sedative and anesthetic activities of the essential oils of Hyptis mutabilis (Rich.) Briq. and their isolated components in silver catfish (Rhamdia quelen)
}

\author{
L.L. Silva ${ }^{1}$, Q.I. Garlet ${ }^{1}$, S.C. Benovit ${ }^{1}$, G. Dolci ${ }^{1}$, C.A. Mallmann ${ }^{2}$, M.E. Bürger ${ }^{1,3}$, \\ B. Baldisserotto ${ }^{1,3}$, S.J. Longhi ${ }^{4}$ and B.M. Heinzmann ${ }^{1,5}$
}

${ }^{1}$ Programa de Pós-Graduação em Farmacologia, Universidade Federal de Santa Maria, Santa Maria, RS, Brasil ${ }^{2}$ Departamento de Medicina Veterinária Preventiva, Universidade Federal de Santa Maria, Santa Maria, RS, Brasil

${ }^{3}$ Departamento de Fisiologia e Farmacologia, Universidade Federal de Santa Maria, Santa Maria, RS, Brasil

${ }^{4}$ Departamento de Ciências Florestais, Unversidade Federal de Santa Maria, Santa Maria, RS, Brasil

${ }^{5}$ Departamento de Farmácia Industrial, Universidade Federal de Santa Maria, Santa Maria, RS, Brasil

\begin{abstract}
This study evaluated the sedative and anesthetic effects of the essential oils (EO) of Hyptis mutabilis (Rich.) Briq. and their isolated components on silver catfish (Rhamdia quelen). Quantitative chemical differences between the EOs obtained from leaves and inflorescences were verified, and a new chemotype rich in globulol was described. Although there were no significant differences in the time of induction for sedation and anesthesia between the EOs, only the leaf EO at $344 \mathrm{mg} / \mathrm{L}$ anesthetized all fish without side effects. Fractionation of the leaf EO was carried out by column chromatography. The isolated compounds [(+)-1-terpinen-4-ol and (-)-globulol] showed different activity from that detected for the leaf EO in proportional concentrations and similar sedation to a eugenol control at $10 \mathrm{mg} / \mathrm{L}$. However, fish exposed to 1-terpinen-4-ol (3 and $10 \mathrm{mg} / \mathrm{L})$ did not remain sedated for $30 \mathrm{~min}$. Anesthesia was obtained with 83-190 mg/L globulol, but animals showed loss of mucus during induction and mortality at these concentrations. Synergism of the depressor effects was detected with the association of globulol and benzodiazepine (BDZ), compared with either drug alone. Fish exposed to BDZ or globulol + BDZ association showed faster recovery from anesthesia in water containing flumazenil, but the same did not occur with globulol. In conclusion, the use of globulol in aquaculture procedures should be considered only at sedative concentrations of 10 and $20 \mathrm{mg} / \mathrm{L}$, and its mechanism of action seems not to involve the $G_{A B A}-B D Z$ system.
\end{abstract}

Key words: Silver catfish; (+)-1-Terpinen-4-ol; (-)-Globulol; Sedation; GABA

\section{Introduction}

Anesthetics are used in aquaculture procedures to immobilize the animals and to prevent stress and pain $(1,2)$. However, some commonly used synthetic compounds induce significant side effects in fish, such as depression of cardiovascular and respiratory function and immunosuppressive effects (3). In this context, essential oils (EOs) and their constituents offer an alternative as a sedative and anesthetic for aquatic animals, and their use has been spreading in recent years (4-8).

The most frequent representative of the genus Hyptis (Lamiaceae) in Southern Brazil is Hyptis mutabilis (Rich.) Briq., known as alfavacão and basil $(9,10)$. In folk medicine, it is used for the treatment of gastritis, headache, and as a healing product, expectorant, and sedative $(11,12)$. Until now, only the antiulcerogenic (13) and antimicrobial (14) activities have been reported for its EO. Distinct major chemical constituents that have been described for the $\mathrm{EO}$ of this plant include $\alpha$-phellandrene, $p$-cymene, $E$-caryophyllene, E-dihydrocarvone, thymol, $\delta$-3-carene, and $E$-methyl cinnamate $(9,13,15,16)$.

In the present study, we evaluated the sedative and anesthetic properties of $H$. mutabilis EOs and their isolated compounds in silver catfish (Rhamdia quelen) in order to identify alternative products for use in aquaculture. In addition, involvement of the GABAergic system in depressor activities of the major isolated compound was evaluated.

Correspondence: B.M. Heinzmann, Departamento de Farmácia Industrial, Universidade Federal de Santa Maria, Avenida Roraima, 1000, Prédio 26, 97105-900 Santa Maria, RS, Brasil. Fax: +55-55-3220-8248. E-mail: berta.heinzmann@gmail.com 


\section{Material and Methods}

\section{Plant material}

Aerial parts of $H$. mutabilis were collected in March 2010, January 2011, and March 2012 in Santa Maria (RS, Brazil). A voucher specimen (No. SMDB 13076) identified by $\mathrm{Dr}$. Solon Jonas Longhi was deposited in the Herbarium of the Departamento de Biologia, Universidade Federal de Santa Maria.

\section{Animals}

Silver catfish ( $R$. quelen) juveniles were purchased from a local fish farm and transported to the laboratory, where they were maintained in continuously aerated 250-L tanks with controlled water parameters. The dissolved oxygen levels (experiment 1: $8.65 \pm 0.07 \mathrm{mg} / \mathrm{L}$; experiments 2 and $3: 7.18 \pm 0.12 \mathrm{mg} / \mathrm{L}$; experiments 4 and 5: $7.10 \pm 0.17 \mathrm{mg} / \mathrm{L}$ ) and temperature (experiment 1 : $15.90 \pm 0.14^{\circ} \mathrm{C}$; experiments 2 and 3 : $19.91 \pm 0.13^{\circ} \mathrm{C}$; experiments 4 and $5: 21.02 \pm 0.11^{\circ} \mathrm{C}$ ) were measured with a YSI-dissolved oxygen meter (YSI Inc., USA). The pH (experiment 1: $7.37 \pm 0.11$; experiments 2 and 3 : $6.70 \pm 0.12$; experiments 4 and 5: $7.11 \pm 0.06)$ was measured with a DMPH-2 pH meter (Digimed, Brazil). Total ammonia levels (experiment 1: $2.43 \pm 0.81 \mathrm{mg} / \mathrm{L}$; experiments 2 and 3: $0.51 \pm 0.17 \mathrm{mg} / \mathrm{L}$; experiments 4 and 5: $1.08 \pm 0.12 \mathrm{mg} / \mathrm{L}$ ) were measured by the salicylate method (17). A semi-static system was used, where $50 \%$ of the water volume was changed daily. Fish were fed once a day with commercial feed (28.0\% crude protein). Juveniles were fasted for a period of $24 \mathrm{~h}$ prior to the experiments. The methodologies were approved by the Ethics and Animal Welfare Committee of the Universidade Federal de Santa Maria (Process No. 46/2010). The number of fish used in each experiment was the lowest possible in order to satisfy the policy of reduction of experimental animals of the institution.

\section{Phytochemical analysis}

Essential oil extraction and analysis. Inflorescence and leaves were submitted separately to a hydrodistillation procedure for $3 \mathrm{~h}$ in a Clevenger-type apparatus (18) and percentage extractive yield was determined $(\mathrm{w} / \mathrm{w})$. Essential oils were stored at $-4^{\circ} \mathrm{C}$ in amber glass bottles until gas chromatography and mass spectrometry (GCMS) analysis, fractionation, and biological testing.

GC-MS was performed using an Agilent-6890 gas chromatograph coupled with an Agilent 5973 mass selective detector using an HP5-MS column (5\% phenyl, $95 \%$ methylsiloxane, $30 \mathrm{~m} \times 0.25 \mathrm{~mm} \mathrm{ID} \times 0.25 \mu \mathrm{m})$ as described by Silva et al. (8). The EO constituents were identified by comparison of the Kovats retention index and mass spectra with a mass spectral library (19), and published data (20).

Isolation and identification. Leaf essential oil obtained in January 2011 was fractionated by column chromatography
(CC) in three repetitions. Each repetition was performed with $2 \mathrm{~g}$ EO added to a column $(3 \times 27 \mathrm{~cm})$ containing $100 \mathrm{~g}$ silica gel 60 (70-230 mesh, Macherey-Nagel, Germany) and eluted with 98:2 (v/v) hexane-acetone at $2 \mathrm{~mL} / \mathrm{min}$. The $20-\mathrm{mL}$ fractions obtained were collected in 15 main fractions (fractions $\mathrm{A}-\mathrm{O}$ ) based on thin-layer chromatography (TLC) profile (silica gel F254; detection: anisaldehyde- $\mathrm{H}_{2} \mathrm{SO}_{4}$ ) and concentrated under reduced pressure at $40^{\circ} \mathrm{C}$. The compound (+)-1-terpinen-4-ol [32.9 mg, yellow oil, El-MS m/z (\%): $154\left(\mathrm{M}^{+}\right)$; $(\alpha)_{D}^{20}=+8.7^{\circ}$ (c $\left.0.023, \mathrm{CHCl}_{3}\right)$ ] was obtained from fraction $\mathrm{G}$ of the first repetition.

Fraction M (405 mg) was applied to a $2 \times 48 \mathrm{~cm}$ column containing $46 \mathrm{~g}$ silica gel 60 impregnated with $10 \%$ silver nitrate (21) and eluted with 95:5 (v/v) hexaneacetone at $1 \mathrm{~mL} / \mathrm{min}$. This CC gives 12 fractions of $20 \mathrm{~mL}$ (M1-12), where M4 corresponded to (-)-globulol [252 mg; white crystalline solid; m.p. $86.9-87^{\circ} \mathrm{C}$; El-MS m/z (\%): $222\left(\mathrm{M}^{+}\right) ;(\alpha)_{\mathrm{D}}{ }^{20}=-41.8^{\circ}$ (c $\left.0.11, \mathrm{CHCl}_{3}\right)$ ]. A larger quantity of this compound $(634.8 \mathrm{mg})$ was purified by CC $(1.9 \times 61.5 \mathrm{~cm})$ under the same conditions described above using the remaining part of fractions $M(755.9 \mathrm{mg})$, M3, and M5 (67.3 mg).

Identification of the isolated compounds was confirmed by GC-MS, ${ }^{1} \mathrm{H}$ and ${ }^{13} \mathrm{C}$ nuclear magnetic resonance (NMR). NMR spectra were recorded in $\mathrm{CDCl}_{3}$ on a Bruker HPX 400 FT-NMR at $400 \mathrm{MHz}$ for ${ }^{1} \mathrm{H}$ and $100 \mathrm{MHz}$ for ${ }^{13} \mathrm{C}$ with tetramethylsilane (TMS) as an internal standard.

\section{Evaluation of the depressor properties}

Two experimental sets were performed to evaluate the sedative and anesthetic potential of the EOs of $H$. mutabilis and their isolated compounds in juvenile silver catfish. In experiment 1 , the anesthetic activity of the leaf and inflorescence EOs extracted in March 2010 were evaluated. Six juveniles $(4.96 \pm 0.56 \mathrm{~g} ; 7.95 \pm 0.25 \mathrm{~cm})$ were used for each concentration tested (172 and $344 \mathrm{mg} / \mathrm{L})$.

The second experiment measured the activity of the isolated compounds in concentrations proportional to those detected in $344 \mathrm{mg} / \mathrm{L}$ leaf EO obtained in March 2012 (3 mg/L 1-terpinen-4-ol and 83 mg/L globulol) in comparison to the same EO. Next, the same substances were evaluated at other concentrations $(10 \mathrm{mg} / \mathrm{L}$ 1-terpinen-4-ol; 10, 20, 50, and $190 \mathrm{mg} / \mathrm{L}$ globulol) to determine the effective concentrations as a sedative and an anesthetic. These concentrations were chosen to allow comparison of the results with other, previously tested, fish anesthetics $(5,6)$. Each concentration was tested in 7 fish $(8.58 \pm 0.21 \mathrm{~g} ; 10.20 \pm 0.13 \mathrm{~cm})$. The EO concentrations were corrected from the density of inflorescence and leaf EOs (March 2010), $0.86 \mathrm{~g} / \mathrm{mL}$, and leaf EO (March 2012), $0.90 \mathrm{~g} / \mathrm{mL}$, before adding to the aquarium water.

Fish were transferred to aquaria containing $1 \mathrm{~L}$ water and the sample to be tested, previously diluted in $95 \%$ 
ethanol (1:10 for EO and 1-terpinen-4-ol, 1:5 for globulol), to evaluate the time required to induce anesthesia (22). Each juvenile was used only once for observation of deep sedation (S2), partial and total loss of equilibrium (S3a and S3b), anesthesia (S4), and/or medullary collapse (S5) (22). The animals remained in the anesthetic bath for 30 min or until reaching S4. Anesthesia was determined by loss of reflex activity and lack of reaction to strong external stimuli. After induction of anesthesia, each fish was measured, weighed, and transferred to an anesthetic-free aquarium to recover. The fish were considered to have recovered if their normal posture and behavior were restored by $30 \mathrm{~min}$. Subsequently, the animals were transferred to $30-\mathrm{L}$ tanks to evaluate possible side effects or mortality until $48 \mathrm{~h}$ after exposure. Control experiments were performed using aquaria containing ethanol at the higher concentration used to dilute the EO and eugenol (Fluka, Switzerland) at 10 and $50 \mathrm{mg} / \mathrm{L}$. Eugenol was used in this study as positive control because it corresponds to the only compound isolated of natural source with anesthetic activity in silver catfish at low concentrations (5).

\section{Involvement of the GABAergic system}

Association with benzodiazepine (BDZ). Sedative concentrations (10 and $20 \mathrm{mg} / \mathrm{L}$ ) of globulol (diluted in $1 \mathrm{~mL} 95 \%$ ethanol) were tested along with BDZ (150 $\mu \mathrm{M}$ diazepam obtained from DEG, in Tween 80 at $0.033 \%$ ) in aquaria containing $1 \mathrm{~L}$ water in this fourth experiment. Controls of BDZ and globulol at the same concentrations were also performed. Eight fish $(32.93 \pm 0.95 \mathrm{~g}$; $15.23 \pm 0.21 \mathrm{~cm}$ ) were tested individually at each concentration. The stages of the induction of anesthesia and recovery time were evaluated as described for the evaluation of the depressor properties. The maximum observation times were $30 \mathrm{~min}$ for induction and $60 \mathrm{~min}$ for recovery.

Reversion of the depressor effects. Fish $(28.34 \pm 1.19 \mathrm{~g}$; $14.60 \pm 0.21 \mathrm{~cm})$ were placed in water containing BDZ (150 $\mu \mathrm{M}$ diazepam), $20 \mathrm{mg} / \mathrm{L}$ globulol, or globulol plus $\mathrm{BDZ}$, at the same concentration as described in Evaluation of the depressor properties and Association with benzodiazepine sections. After induction, animals were transferred to an anesthetic-free aquarium containing either the classic BDZ antagonist flumazenil $(5 \mu \mathrm{M}$, Flumazil ${ }^{\mathbb{R}}$, Cristália, Brazil) or water. Fish behavior was scored 1, 5, 10, 15, and 20 min after the transfer according to the protocol described by Heldwein et al. (23). After $20 \mathrm{~min}$, scores for each fish $(n=5$ for each recovery treatment) were summed.

\section{Statistical analysis}

Data are reported as means \pm SE. The homogeneity of variances and normality of data were verified with Levene and Kolmogorov-Smirnov tests, respectively. Log transformations were performed before statistical analysis when appropriate. Comparisons of activity of the leaf and inflorescence EOs at the same concentration, between concentrations of the isolated compound and between recovery treatments in the reversion experiment were performed with the $t$-test or the Mann-Whitney test. Anesthetic effects of EO or eugenol compared with the isolated compounds were analyzed by one-way ANOVA and Tukey or Kruskall-Wallis and Dunn tests. Two-way ANOVA and the Tukey test or Scheirer-Ray-Hare extension of the Kruskal-Wallis test and the Dunn test were used to evaluate the association in comparison to globulol and BDZ alone. Analysis was performed using the SigmaPlot version 11.0 software, and the minimum significance level was set at $\mathrm{P}<0.05$.

\section{Results}

\section{Phytochemical analysis}

In the extractive yield of $H$. mutabilis, the EO was higher from inflorescences $(0.28 \%)$ than from leaves $(0.25 \%)$. Quantitative differences in composition were detected between the EOs of the different parts of the plant. Globulol (26.61\%) was the major compound of leaf EO in the two collection periods evaluated, while inflorescence EO was rich in germacrene D (14.97\%; Table 1). The fractionation of leaf EO resulted in isolation of two compounds that were identified as 1-terpinen-4-ol and globulol according to the literature $(19,20,24-26)$.

\section{Evaluation of depressor properties}

Silver catfish exposed to leaf and inflorescence EOs did not show significant differences in the induction time for deep sedation and anesthesia (Figure 1). However, only $33 \%$ of fish were anesthetized with $344 \mathrm{mg} / \mathrm{L}$ inflorescence EO, whereas all animals reached this stage with leaf EO. At $172 \mathrm{mg} / \mathrm{L}$, leaf EO promoted S3b anesthesia in all animals exposed, but only 1 fish (17\%) reached this stage with the inflorescence EO (1578 s). Ethanol alone did not produce any anesthetic or sedative effect.

Total recovery was observed in all animals within $2 \mathrm{~h}$. During the $30 \mathrm{~min}$ of observation, about half the fish exposed to leaf EO and two animals (33\%) exposed to $344 \mathrm{mg} / \mathrm{L}$ inflorescence EO returned to normal behavior. Side effects were observed in $30 \%$ of the fish exposed to inflorescence EO during recovery time, and they were independent of the concentration tested. There were hyperactivity episodes, where spasms and/or "corkscrewlike" circling swimming behavior could be observed, followed by an immobile period and a return to swimming, with partial loss of equilibrium. Mortality or other side effects were not observed in either sample $48 \mathrm{~h}$ after exposure.

The induction time to stages of anesthesia was shorter for fish exposed to $344 \mathrm{mg} / \mathrm{L}$ EO than to the isolated compounds in proportional concentrations. The only 
Table 1. Chemical composition of essential oils (EO) of Hyptis mutabilis.

\begin{tabular}{|c|c|c|c|c|c|}
\hline \multirow[t]{2}{*}{ Components } & \multicolumn{3}{|c|}{ Relative percentage } & \multirow[t]{2}{*}{ RI cal } & \multirow[t]{2}{*}{ RI ref } \\
\hline & IEO & LEO 1 & LEO 2 & & \\
\hline$\alpha$-thujene & 4.258 & 1.649 & 6.001 & 925 & $925^{a}$ \\
\hline$\alpha$-pinene & 7.27 & 1.096 & 3.713 & 930 & $933^{a}$ \\
\hline 4(10)-thujene & & & 2.027 & 970 & $968^{a}$ \\
\hline$\beta$-pinene & 7.906 & 2.897 & 1.915 & 972 & $970^{a, b}$ \\
\hline 1-octen-3-ol & 0.774 & 1.233 & 1.27 & 980 & $979^{a, b}$ \\
\hline Limonene & 1.34 & 1.731 & 1.636 & 1025 & $1029^{a}$ \\
\hline$\tau$-terpinene & 0.385 & 0.199 & 0.715 & 1056 & $1056^{a}$ \\
\hline$(+)$-1-terpinen-4-ol & 0.712 & 0.395 & 0.886 & 1175 & $1174^{\mathrm{a}}$ \\
\hline$\alpha$-copaene & 2.364 & 2.647 & 1.694 & 1377 & $1377^{a, b}$ \\
\hline$\beta$-bourbonene & 0.787 & 1.492 & 1.532 & 1386 & $1384^{a}$ \\
\hline$\beta$-cubebene & 0.875 & 1.172 & 0.693 & 1391 & $1389^{a}$ \\
\hline$(-)$ - $\beta$-elemene & 0.789 & 0.552 & 0.554 & 1393 & $1393^{\mathrm{a}}$ \\
\hline E-caryophyllene & 12.424 & 10.839 & 13.948 & 1423 & $1419^{a, b}$ \\
\hline$\alpha$-caryophyllene & 2.434 & 3.95 & 2.54 & 1455 & $1455^{a, b}$ \\
\hline Germacrene D & 14.968 & 6.936 & 8.697 & 1484 & $1485^{a}$ \\
\hline Bicyclogermacrene & 10.895 & 7.845 & 9.048 & 1499 & $1500^{\mathrm{b}}$ \\
\hline Germacrene A & 0.906 & 0.874 & 0.591 & 1506 & $1509^{b}$ \\
\hline$\gamma$-cadinene & & & 0.994 & 1513 & $1514^{\mathrm{a}}$ \\
\hline Cubebol & 1.085 & 2.06 & & 1517 & $1515^{\mathrm{b}}$ \\
\hline$(+)$ - $\delta$-cadinene & 2.166 & 1.966 & 1.188 & 1525 & $1523^{a}$ \\
\hline Spathulenol & & & 1.401 & 1577 & $1578^{a, b}$ \\
\hline Germacrene D-4-ol & 0.875 & & & 1580 & $1576^{a, b}$ \\
\hline \multirow[t]{2}{*}{ (-)-globulol } & 11.604 & 26.61 & 24.232 & 1587 & 1585 \\
\hline & & & & 1593 & $1592^{\mathrm{a}, \mathrm{b}}$ \\
\hline \multirow[t]{2}{*}{ Viridiflorol } & 0.664 & 1.14 & 0.835 & 1592 & 1593 \\
\hline & & & & 1597 & $1595^{a, b}$ \\
\hline Humulene epoxide II & 0.426 & 1.336 & & 1613 & $1608^{b}$ \\
\hline 1-epi-cubenol & 0.419 & 0.837 & 0.388 & 1632 & $1629^{b}$ \\
\hline Caryophylla-4(14),8(15)-dien-5 $\alpha$-ol & & 0.797 & 0.37 & 1636 & $164^{\mathrm{b}}$ \\
\hline Caryophylla-4(14),8(15)-dien-5 $\beta$-ol & & 1.127 & 0.811 & 1640 & $1641^{\mathrm{b}}$ \\
\hline$\tau$-muurolol & 1.109 & 1.434 & 0.597 & 1645 & $1645^{a}$ \\
\hline$(-)-\delta$-cadinol & 0.384 & 0.589 & 0.396 & 1649 & $1648^{a}$ \\
\hline$\alpha$-cadinol & 1.359 & 1.759 & 0.82 & 1658 & $1654^{\mathrm{a}}$ \\
\hline Total identified (\%) & 95.679 & 95.882 & 91.126 & & \\
\hline
\end{tabular}

LEO: leaf EO collected in March 2010 (1) and March 2012 (2); IEO: inflorescence EO; RI cal: calculated Kovats retention index; RI ref: reference Kovats retention index. ${ }^{\mathrm{a}} \mathrm{NIST}(19) ;{ }^{\mathrm{b}}$ Adams (20). Bold type indicates isolated constituents. Components in amount below $0.5 \%$ have been omitted.

exception to this pattern occurred with globulol in stage $3 a$ (Table 2). The exposure to 1-terpinen-4-ol (3 and $10 \mathrm{mg} /$ L) was able to promote only deep sedation in the juveniles, with significant differences between concentrations (Table 2). However, the fish showed signs of recovery by $30 \mathrm{~min}$ of exposure to both concentrations of 1-terpinen-4-ol. Higher concentrations of 1-terpinen-4ol were not evaluated in this study due to the small quantity obtained from the isolation process and its high volatility from the anesthetic bath.

Concentrations of 10 and $20 \mathrm{mg} / \mathrm{L}$ globulol induced to stages 2 and $3 a$, but $190 \mathrm{mg} / \mathrm{L}$ anesthetized (stage 4) all exposed fish in about $13 \mathrm{~min}$. Intermediate concentrations (50 and $83 \mathrm{mg} / \mathrm{L}$ ) promoted stages $3 \mathrm{~b}$ and 4 in $14-71 \%$ of the fish tested. A positive relationship between an increase of drug concentration and a decrease in the time required for anesthesia induction was observed for all stages (Table 2).

Only fish exposed to $10 \mathrm{mg} / \mathrm{L}$ globulol recovered during the observation period $(195.4 \pm 25.6 \mathrm{~s})$. For the other concentrations, the time of recovery exceeded 30 min (data not shown). "C-shaped" contractions and/ or circular swimming followed by a motionless period were observed in the recovery period after exposure to 20 and 

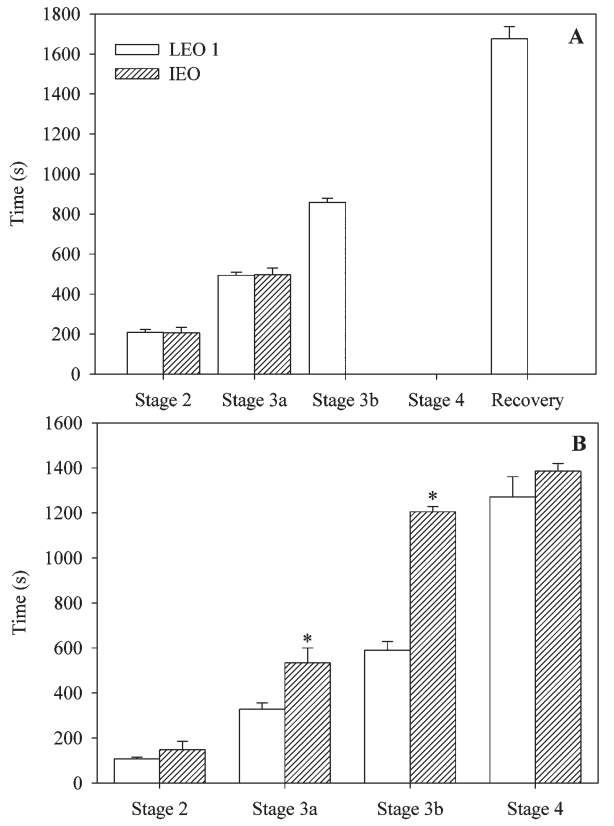

Figure 1. Anesthetic activity of essential oils (EO) of Hyptis mutabilis obtained from leaf (LEO 1) and inflorescence (IEO) at concentrations of $172 \mathrm{mg} / \mathrm{L}(A)$ and $344 \mathrm{mg} / \mathrm{L}(B)$ in silver catfish juveniles. Stages of anesthesia: deep sedation (stage 2), partial loss of equilibrium (stage 3a), total loss of equilibrium (stage 3b), and anesthesia (stage 4) (22). Maximum observation time was $30 \mathrm{~min}$. Time to reach each stage is given in seconds (s). Data are reported as means $\pm S E(n=6)$. ${ }^{*} P<0.05$, compared to LEO 1 ( $t$-test or Mann-Whitney U-test).

$50 \mathrm{mg} / \mathrm{L}$ globulol. Mortality within $48 \mathrm{~h}$ after testing occurred in animals exposed to 83 and $190 \mathrm{mg} / \mathrm{L}$ globulol (29 and $57 \%$, respectively), as well as loss of mucus during induction.

Statistically significant differences between 1-terpinen-4-ol and eugenol controls in induction time were not detected until stage 2 at $10 \mathrm{mg} / \mathrm{L}$. Fish exposed to globulol (10 and $50 \mathrm{mg} / \mathrm{L}$ ) needed more time to reach this stage than those exposed to eugenol or 1-terpinen-4ol at equal concentrations (Table 2). Recovery occurred faster with juveniles exposed to $10 \mathrm{mg} / \mathrm{L}$ globulol than those sedated with eugenol at the same concentration $(411.4 \pm 73.0 \mathrm{~s})$. At $50 \mathrm{mg} / \mathrm{L}$, only animals exposed to eugenol recovered during the observation time $(508.4 \pm 11.4 \mathrm{~s})$.

\section{Involvement of the GABAergic system}

$A$ reduction in the time required to reach most of the stages of anesthesia and a higher depression level were observed with the association of BDZ and globulol (Figure 2). Among the fish exposed to $150 \mu \mathrm{M} \mathrm{BDZ}$ and to $10 \mathrm{mg} / \mathrm{L}$ globulol, 75 and $25 \%$, respectively, reached stage $3 a$ during the observation time. However, some fish exposed to the association reached stage $3 b(37.5 \%$ with $10 \mathrm{mg} / \mathrm{L}$ globulol + BDZ, and 75\% with $20 \mathrm{mg} / \mathrm{L}$ globulol + BDZ) and stage $4(50 \%$ with $20 \mathrm{mg} / \mathrm{L}$ globulol $+B D Z$, in $1617.5 \pm 94.0 \mathrm{~s})$. An irregular recovery pattern was also observed in this experiment. Only fish exposed to BDZ presented $100 \%$ recovery within $60 \mathrm{~min}$, whereas return to normal behavior occurred in $43.7-75 \%$ of the animals exposed to globulol or its association with BDZ.

During the reversal of depressive effect, a higher total score corresponds to faster recovery. Fish exposed to $\mathrm{BDZ}$ had a higher total score when $5 \mu \mathrm{M}$ flumazenil was added to the water compared with those fish that recovered in water alone (Figure 3 ). The same pattern occurred when the two agents were combined, but not with globulol alone.

\section{Discussion}

\section{Phytochemical analysis}

The EO content extracted from both parts of the plant was within the range described for EOs obtained from aerial parts of $H$. mutabilis collected in different localities $(0.1-2.1 \%)$ (9). The same pattern was not verified in relation to the chemical composition of the EOs from the leaves and inflorescences $(9,13-16,27)$. Globulol was one of the major compounds in leaf and inflorescence EOs. It was also detected in high amounts (11.9\%) in the EO obtained from aerial parts of this species collected in Retiro das Pedras (State of Amapá, North of Brazil). However, those samples contained $\delta$-3-carene (25.5\%) and terpinolene $(24.7 \%)$ as additional major components (9), which characterize them as a chemotype distinct from those detected in this study.

\section{Evaluation of the depressor properties}

The anesthetic activity detected for the EO was not surprising, since $H$. mutabilis is used as a sedative in folk medicine (12). Silver catfish reached the anesthesia stage around 21-23 min with $344 \mathrm{mg} / \mathrm{L}$ EO obtained from leaves and inflorescences. Other fish anesthetics in similar concentrations are able to induce anesthesia in less time. For example, the EO of Lippia alba (300-500 mg/L) anesthetized silver catfish in 1-4 $\min (4)$.

There are only a few reports on the anesthetic and sedative properties of isolated plant compounds in aquatic animals, and those only evaluated the effects of eugenol and menthol $(5,6,28,29)$. In this study, the depressor effects of 1-terpinen-4-ol and globulol obtained from EO of $H$. mutabilis were characterized in silver catfish. These effects did not correspond to the leaf EOs from which they were isolated, which suggests a synergic action between the EO constituents.

The sedative effect of 1-terpinen-4-ol is reported to be higher or similar to that of eugenol at the same concentrations in silver catfish (28). However, the use of 1-terpinen-4-ol in place of eugenol is not advisable, because it was not able to maintain this stage for 
Table 2. Time required for induction of anesthesia in silver catfish juveniles with globulol and 1-terpinen-4-ol, in comparison with EO of Hyptis mutabilis (LEO 2) and eugenol (positive control).

\begin{tabular}{|c|c|c|c|c|}
\hline \multirow[t]{2}{*}{ Compound (mg/L) } & \multicolumn{4}{|c|}{ Induction time (s) } \\
\hline & Stage 2 & Stage $3 a$ & Stage $3 b$ & Stage 4 \\
\hline \multicolumn{5}{|l|}{ Globulol } \\
\hline 10 & $1331.4 \pm 124.8^{*}$ & & & \\
\hline 20 & $325.3 \pm 28.0$ & $717.9 \pm 70.6$ & & \\
\hline 50 & $107.3 \pm 1.6^{*}$ & $139.3 \pm 9.1^{*}$ & $1041.5 \pm 25.5^{*}$ & $\#$ \\
\hline 83 & $44.7 \pm 5.3^{B}$ & $116.6 \pm 19.0^{A}$ & $1056.2 \pm 63.7^{A}$ & $1247.0 \pm 95.7^{\mathrm{Aa}}$ \\
\hline 190 & $14.1 \pm 2.5$ & $148.0 \pm 10.6$ & $502.0 \pm 7.9$ & $779.1 \pm 55.0^{\mathrm{b}}$ \\
\hline Equation & $\begin{array}{c}y=115.27+6732.71 \\
\exp ^{-0.17 x}-0.56 x\left(r^{2}=0.999\right)\end{array}$ & $\begin{array}{c}y=89.68+4297.40 \\
\exp ^{-0.0966 x}+0.31 \times\left(r^{2}=1.0\right)\end{array}$ & $\begin{array}{c}y=852.49+5.79 x- \\
0.04 x^{2}\left(r^{2}=1.0\right)\end{array}$ & \\
\hline \multicolumn{5}{|l|}{ 1-terpinen-4-ol } \\
\hline 3 & $946.8 \pm 65.0^{\mathrm{Aa}}$ & & & \\
\hline 10 & $300.9 \pm 42.8^{\mathrm{b}}$ & & & \\
\hline \multicolumn{5}{|l|}{ LEO 2} \\
\hline 344 & $25.3 \pm 3.7^{C}$ & $93.0 \pm 16.6^{A}$ & $566.4 \pm 66.6^{\mathrm{B}}$ & $796.3 \pm 68.2^{\mathrm{B}}$ \\
\hline \multicolumn{5}{|l|}{ Eugenol } \\
\hline 10 & $165.7 \pm 19.7$ & $226.0 \pm 19.1$ & & \\
\hline 50 & $35.7 \pm 6.0$ & $60.6 \pm 2.9$ & $363.7 \pm 18.6$ & $549.7 \pm 26.5$ \\
\hline
\end{tabular}

Stages are according to Schoettger and Julin (22). Maximum observation time was $30 \mathrm{~min}$. Data are reported as means $\pm S E(n=7)$. \# Only 1 fish reached this stage of induction (1767s) until $30 \mathrm{~min}$. Different lowercase letters in the columns indicate significant difference among concentrations of the same compound using the $t$-test $(\mathrm{P}<0.05)$. Different uppercase letters in the columns indicate significant differences between LEO 2 and isolated compound at proportional concentrations (83 mg/L of globulol and $3 \mathrm{mg} / \mathrm{L} 1$ terpinen-4-ol) using one-way ANOVA and the Tukey test $(\mathrm{P}<0.05)$. ${ }^{*}$ Statistically different from eugenol at the same concentration by Kruskall-Wallis and Dunn tests $(P<0.05)$. In equations, $x$ : concentration of compound $(\mathrm{mg} / \mathrm{L})$; $y$ : time to reach the stage of induction or recovery from anesthesia in seconds (s).

$30 \mathrm{~min}$. In this context, globulol at $10 \mathrm{mg} / \mathrm{L}$ seems to have a better pharmacological profile. Despite its induction time being about 10 -fold higher than eugenol, its low concentration effectiveness and fast recovery after exposure are positive points for its use as a sedative. Low concentrations of anesthetics are used for long exposures during fish transport, aiming to reduce stress and injury $(28,30)$ Anesthetic activity of globulol was observed at concentrations from 83 to $190 \mathrm{mg} / \mathrm{L}$ with an induction time of $13-21 \mathrm{~min}$. A similar concentration range of menthol (100-200 mg/L) induces anesthesia within $10 \mathrm{~min}$ in tambaqui (Colossoma macropomum) and pacu
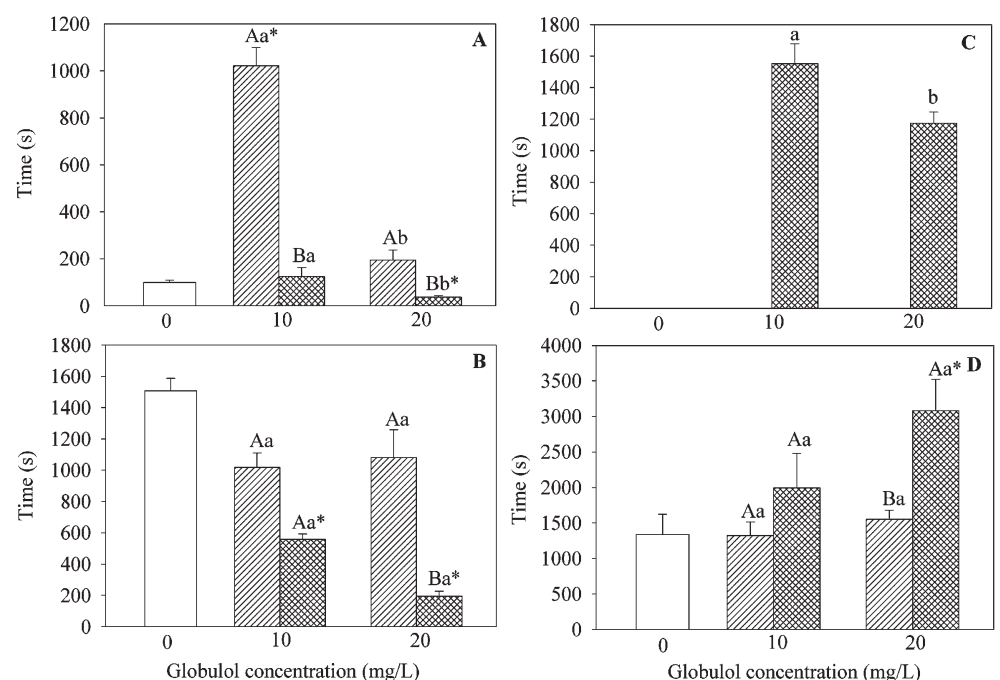

Figure 2. Time required for induction of anesthesia in silver catfish with globulol in association with benzodiazepine (BDZ): stage $2(A)$, stage 3a $(B)$ and stage $3 \mathrm{~b}(C)$ according to Schoettger and Julin (22), and recovery time $(D)$. Maximum observation time was 30 min to induction and $60 \mathrm{~min}$ to recovery. Time to reach each stage is given in seconds (s). Data are reported as means \pm SE $(n=8)$. *Significantly different compared to BDZ; different uppercase letters indicate significant differences between globulol and association (globulol+BDZ) at the same concentration; different lowercase letters indicate significant differences between concentrations of the same group. Two-way ANOVA and the Tukey test or Scheirer-Ray-Hare extension of the Kruskal-Wallis test and the Dunn test were used $(P<0.05)$. The control group of vehicle treatment is omitted because it did not produce any stage of anesthesia. 


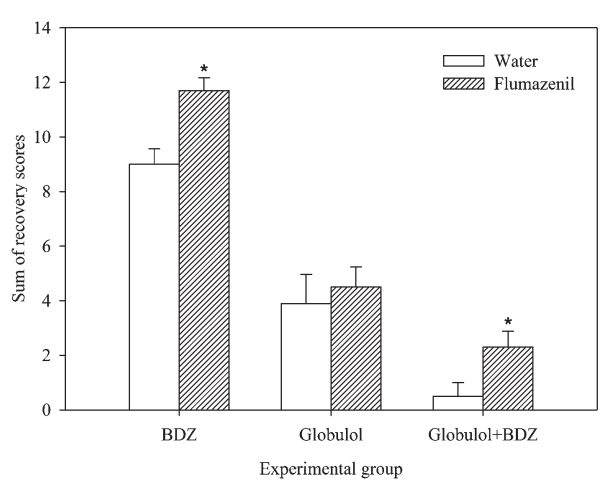

Figure 3. Sum of recovery scores for silver catfish exposed to $20 \mathrm{mg} / \mathrm{L}$ globulol, $150 \mu \mathrm{M}$ benzodiazepine (BDZ), and the association (globulol+BDZ) at the same concentrations. Data are reported as means $\pm \operatorname{SE}(n=5)$. ${ }^{*} P<0.05$, compared to treatment with water $(t$-test).

(Piaractus mesopotamicus) (6,29). Eugenol requires a lower concentration and less time to induce this depression level in silver catfish $(20-50 \mathrm{mg} / \mathrm{L} ; 1.6-15 \mathrm{~min})$ and pacu $(25-100 \mathrm{mg} / \mathrm{L} ; 0.8-3.5 \mathrm{~min})(5,6)$.

Loss of mucus during induction and mortality after exposure were observed at the highest globulol concentrations, but these effects are also commonly observed with some synthetic anesthetics used in aquaculture, such as benzocaine $(1,31-33)$.

The irregular pattern of anesthetic induction observed with some anesthetic concentrations or samples can result from individual differences in fish responsiveness. The presence of high and low responders within the same fish family was previously described in relation to cortisol release (34). However, other studies should be performed to confirm this hypothesis.

The long recovery time detected for all the drugs tested could be due to their hydrophobic characteristics. Kiessling et al. (2) confirmed that isoeugenol, a lipophilic compound, exhibits slower clearance than the hydrophilic drug MS-222 in Atlantic salmon (Salmo salar). Slow clearance may be associated with drug accumulation in adipose tissue, which in turn would increase the recovery time after long exposure $(2,3)$.

\section{Involvement of the GABAergic system}

The evaluation of a drug's mechanism of action may include experiments using synergism and/or reversal of effect by a pharmacological antagonist $(35,36)$. In this study, these two strategies were used to assess the

\section{References}

1. Inoue LAKA, Neto CS, Moraes G. Clove oil as anesthesic for juveniles of matrinxã Brycon cephalus (Gunther, 1969). Cienc Rural 2003; 33: 937-943, doi: 10.1590/S010384782003000500022 . involvement of the GABAergic system in globulol's mechanism. Gamma-aminobutyric acid (GABA) is the main inhibitory neurotransmitter in the vertebrate brain, and its ionotropic receptors are widely recognized as targets of action of sedative and anesthetic compounds. Benzodiazepine drugs, such as diazepam, are positive allosteric modulators of the $\mathrm{GABA}_{\mathrm{A}}$ receptor, and they increase the opening frequency of the GABA-gated chloride channel (37).

Clear synergic behavior was detected when globulol and diazepam were associated at sedative concentrations. Similar results were observed for sedation induced by the EOs of $L$. alba and $O$. gratissimum using the same protocol $(8,23)$. However, as opposed to those results, globulol alone seems to act independently of flumazenilsensitive benzodiazepine sites on the GABA receptor. Thus, the sedative properties of globulol could be the result of action at another site on the GABA receptor or at a different receptor.

On the other hand, the abnormal behavior observed in fish exposed to globulol at $20-50 \mathrm{mg} / \mathrm{L}$ may be indicative of anti-glutamatergic activity. Riehl et al. (38) reported circular swimming behavior without spiraling rotations in zebrafish (Danio rerio) exposed to sub-anesthetic doses of ketamine, and related these effects to antagonist action on N-methyl-D-aspartate glutamate receptors. As globulol behavior seems to be distinct from that found for inflorescence EO, additional studies should be performed to explain these effects and to study globulol action on glutamate receptors.

In conclusion, sedative and anesthetic properties of EOs of $H$. mutabilis and their isolated compounds (1-terpinen-4-ol and globulol) were verified in silver catfish. The biological action and chemical composition of the EOs were influenced by the part of the plant from which they were obtained. Of the samples tested, globulol was the only one with potential application as a sedative for aquatic animals. Its effect seemed not to involve the $\mathrm{GABA}_{\mathrm{A}}$-benzodiazepine receptor.

\section{Acknowledgments}

Research supported by FAPERGS/PRONEX (\#10/ 0016-8) and CNPq (\#470964/2009-0). B. Baldisserotto, C.A. Mallmann, M.E. Bürger, and S.J. Longhi are grateful to CNPq for research fellowships; L.L. Silva, S.C. Benovit, and G. Dolci are grateful to CAPES for their postgraduate fellowships. Q.I. Garlet is grateful to FIT/UFSM for her undergraduate scholarship.
2. Kiessling A, Johansson D, Zahl IH, Samuelsen OB. Pharmacokinetics, plasma cortisol and effectiveness of benzocaine, MS-222 and isoeugenol measured in individual dorsal aorta-cannulated Atlantic salmon (Salmo salar) 
following bath administration. Aquaculture 2009; 286: 301308, doi: 10.1016/j.aquaculture.2008.09.037.

3. Zahl IH, Samuelsen O, Kiessling A. Anaesthesia of farmed fish: implications for welfare. Fish Physiol Biochem 2012; 38: 201-218, doi: 10.1007/s10695-011-9565-1.

4. Cunha MA, Barros FMC, Garcia LO, Veeck APL, Heinzmann $\mathrm{BM}$, Loro VL, et al. Essential oil of Lippia alba: a new anesthetic for silver catfish, Rhamdia quelen. Aquaculture 2010; 306: 403-406, doi: 10.1016/j.aquaculture.2010.06.014.

5. Cunha MA, Zeppenfeld CC, Garcia LO, Loro VL, Fonseca $\mathrm{MB}$, Emanuelli $\mathrm{T}$, et al. Anesthesia of silver catfish with eugenol: time of induction, cortisol response and sensory analysis of fillet. Cienc Rural 2010; 40: 2107-2114, doi: 10.1590/S0103-84782010005000154.

6. Gonçalves AFN, Santos ECC, Fernandes JBK, Takahashi LS. Menthol and eugenol as benzocaine substitutes in anesthetic induction of pacu juveniles. Acta Sci Anim Sci 2008; 30: 339-344.

7. Hajek GJ. The anaesthetic-like effect of tea tree oil in common carp Cyprinus carpio L. Aquaculture Res 2011; 42: 296-300, doi: 10.1111/j.1365-2109.2010.02625.x.

8. Silva LL, Parodi TV, Reckziegel P, Garcia VO, Bürger ME, Baldisserotto $\mathrm{B}$, et al. Essential oil of Ocimum gratissimum L.: Anesthetic effects, mechanism of action and tolerance in silver catfish, Rhamdia quelen. Aquaculture 2012; 350-353: 91-97, doi: 10.1016/j.aquaculture.2012.04.012.

9. Aguiar EHA, Zoghbi MGB, Silva MHL, Maia JGS, Amasifen JMR, Rojas UM. Chemical variation in the essential oils of Hyptis mutabilis (Rich.) Briq. J Essent Oil Res 2003; 15: 130-132, doi: 10.1080/10412905.2003.9712089.

10. Kissmann KG, Groth D. Plantas infestantes e nocivas. São Paulo: BASF S.A.; 1995.

11. de Albuquerque UP, Muniz de MP, de Almeida AL, Monteiro JM, Machado de Freitas Lins Neto, Gomes de MJ, et al. Medicinal plants of the caatinga (semi-arid) vegetation of NE Brazil: a quantitative approach. J Ethnopharmacol 2007; 114: 325-354, doi: 10.1016/j.jep.2007.08.017.

12. Amorim $C C$, Boff $P$. Ethnobotany of Land Medicine in the Coxilha Rica Region, SC. Rev Bras Agroecol 2009; 4: 15951599.

13. Barbosa PPP, Ramos CP. Studies on the antiulcerogenic activity of the essential oil of Hyptis mutabilis Briq. in rats. Phytother Res 2013; 6: 114-115, doi: 10.1002/ptr.2650060214.

14. Oliva MM, Demo MS, Lopez AG, Lopez ML, Zygadlo JA. Antimicrobial activity and composition of Hyptis mutabilis essential oil. J Herbs Spices Med Plants 2006; 11: 57-63, doi: 10.1300/J044v11n04_07.

15. Luz AIR, Zoghbi MGB, Ramos LS, Maia JGS, Silva ML. Essential oils of some Amazonian Labiatae, 1. Genus Hyptis. J Nat Prod 1984; 47: 745-747, doi: 10.1021/np50034a044.

16. Velasco-Negueruela $A$, Perez-Alonso MJ, Esteban JL, Guzman CA, Zygadlo JA, Espinar LA. Volatile constituents of Hyptis mutabilis (Rich.) Briq. J Essent Oil Res 1995; 7: 81-82, doi: 10.1080/10412905.1995.9698469.

17. Verdouw H, Van Echteld CJA, Dekkers EMJ. Ammonia determination based on indophenol formation with sodium salicylate. Water Res 1978; 12: 399-402, doi: 10.1016/ 0043-1354(78)90107-0.

18. Anonymous. European Pharmacopeia. 6th edn. Strassbourg: European Directorate for the Quality of Medicines; 2007.

19. Anonymous. NIST/EPA/NIH mass spectral library and search/analysis programs. Hoboken: J. Wiley and Sons; 2005.

20. Adams RP. Identification of essential oil components by gas chromatography/quadrupole mass spectroscopy. Allured Publishing Corporation, Illinois; 2001.

21. Williams CM, Mander LN. Chromatography with silver nitrate. Tetrahedron 2001; 57: 425-447, doi: 10.1016/ S0040-4020(00)00927-3.

22. Schoettger RA, Julin M. Efficacy of MS-222 as an anesthetic on four salmonids. Invest Fish Contr 1967; 13: 1-15.

23. Heldwein CG, Silva LL, Reckziegel $P$, Barros FM, Burger $\mathrm{ME}$, Baldisserotto $\mathrm{B}$, et al. Participation of the GABAergic system in the anesthetic effect of Lippia alba (Mill.) N.E. Brown essential oil. Braz J Med Biol Res 2012; 45: 436-443, doi: 10.1590/S0100-879X2012007500052.

24. Faure R, Ramanoelina ARP, Rakotonirainy O, Bianchini JP, Gaydou EM. Two-dimensional nuclear magnetic resonance of sesquiterpenes. 4 - Application to complete assignment of ${ }^{1} \mathrm{H}$ and ${ }^{13} \mathrm{C}$ NMR spectra of some aromadendrane derivatives. Magn Reson Chem 1991; 29: 969-971, doi: 10.1002/mrc. 1260290920.

25. SDBS. Spectral Database for Organic Compounds. National Institute of Advanced Industrial Science and Technology. http://riodb01.ibase.aist.go.jp/sdbs/.

26. Toyota M, Tanaka M, Asakawa $\mathrm{Y}$. A revision of the ${ }^{13} \mathrm{C}$ NMR spectral assignment of globulol. Spectroscopy 1999; 14: 61-66, doi: 10.1155/1999/725956.

27. Bailac P, Duschatzky C, Ponzi M, Firpo N. Essential oil of Hyptis mutabilis (Rich.) Briq. grown in San Luis, Argentina. $J$ Essent Oil Res 1999; 11: 217-219, doi: 10.1080/ 10412905.1999.9701115.

28. Becker AG, Parodi TV, Heldwein CG, Zeppenfeld CC, Heinzmann BM, Baldisserotto B. Transportation of silver catfish, Rhamdia quelen, in water with eugenol and the essential oil of Lippia alba. Fish Physiol Biochem 2012; 38: 789-796, doi: 10.1007/s10695-011-9562-4.

29. Façanha MF, Gomes LC. Efficacy of menthol as an anesthetic for tambaqui (Colossoma macropomum, Characiformes: Characidae). Acta Amaz 2005; 35: 71-75, doi: 10.1590/S0044-59672005000100011.

30. Cooke SJ, Suski CD, Ostrand KG, Tufts BL, Wahl DH. Behavioral and physiological assessment of low concentrations of clove oil anaesthetic for handling and transporting largemouth bass (Micropterus salmoides). Aquaculture 2004; 239: 509-529, doi: 10.1016/j.aquaculture.2004.06.028.

31. Velisek J, Wlasow T, Gomulka P, Svobodova Z, Novotny L. Effects of 2-phenoxyethanol anaesthesia on sheatfish (Silurus glanis L.). Vet Med-Czech 2007; 52: 103-110.

32. Ghanawi J, Monzer S, Saoud IP. Anaesthetic efficacy of clove oil, benzocaine, 2-phenoxyethanol and tricaine methanesulfonate in juvenile marbled spinefoot (Siganus rivulatus). Aquaculture Res 2013; 44: 359-366, doi: 10.1111/j.1365-2109.2011.03039.x.

33. Small BC. Anesthetic efficacy of metomidate and comparison of plasma cortisol responses to tricaine methanesulfonate, quinaldine and clove oil anesthetized channel catfish Ictalurus punctatus. Aquaculture 2003; 218: 177-185, doi: 10.1016/S0044-8486(02)00302-2.

34. Ellis T, Yildiz HY, Lopez-Olmeda J, Spedicato MT, Tort L, Overli $\mathrm{O}$, et al. Cortisol and finfish welfare. Fish Physiol 
Biochem 2012; 38: 163-188, doi: 10.1007/s10695-0119568-y.

35. Schultz MK, Wright LK, Stone MF, Schwartz JE, Kelley NR, Moffett MC, et al. The anticholinergic and antiglutamatergic drug caramiphen reduces seizure duration in somanexposed rats: synergism with the benzodiazepine diazepam. Toxicol Appl Pharmacol 2012; 259: 376-386, doi: 10.1016/j.taap.2012.01.017.

36. Tamboli AM, Rub RA, Ghosh P, Bodhankar S. Antiepileptic activity of lobeline isolated from the leaf of Lobelia nicotianaefolia and its effect on brain GABA level in mice. Asian Pac J Trop Biomed 2012; 2: 537-542, doi: 10.1016/ S2221-1691(12)60092-6.

37. Korpi ER, Grunder G, Luddens H. Drug interactions at GABA(A) receptors. Prog Neurobiol 2002; 67: 113-159, doi: 10.1016/S0301-0082(02)00013-8.

38. Riehl R, Kyzar E, Allain A, Green J, Hook M, Monnig L, et al. Behavioral and physiological effects of acute ketamine exposure in adult zebrafish. Neurotoxicol Teratol 2011; 33: 658-667, doi: 10.1016/j.ntt.2011.05.011. 